Article

\title{
An Investigation of Reverse Flotation Separation of Sericite from Graphite by Using a Surfactant: MF
}

\author{
Yangshuai Qiu ${ }^{1}$, Yongfu Yu ${ }^{1,2, *}$, Lingyan Zhang ${ }^{1,2}$, Yupeng Qian ${ }^{1,2}$ and Zhijun Ouyang ${ }^{1}$ \\ 1 School of Resources and Environmental Engineering, Wuhan University of Technology, Luoshi Road 122, \\ Wuhan 430070, China; liucanviva@whut.edu.cn (Y.Q.); zhly@whut.edu.cn (L.Z.); \\ qianyupeng@whut.edu.cn (Y.Q.); 15071484549@whut.edu.cn (Z.O.) \\ 2 Hubei Province Key Laboratory for Processing of Mineral Resources and Environment, Luoshi Road 122, \\ Wuhan 430070, China \\ * Correspondence: yuyongfu201506@163.com or yyf1022@whut.edu.cn; Tel./Fax: +86-27-8788-2128
}

Academic Editor: Massimiliano Zanin

Received: 7 April 2016; Accepted: 7 June 2016; Published: 23 June 2016

\begin{abstract}
In this paper, a surfactant, atlox4862 (formaldehyde condensate of methyl naphthalene sulfonic sodium salt) (MF), was introduced as a depressant for reverse flotation separation of sericite from graphite. Natural flake graphite has a strong hydrophobic property. After interacting with MF, the graphite became moderately hydrophilic. The flotation results showed that MF had a depressing ability for both sericite and graphite and that the flotation separation of sericite from graphite was attributed to the different declining levels of recovery between graphite and sericite with increased MF concentration. For a pulp pH of 8 and a MF concentration of $250 \mathrm{mg} / \mathrm{L}$, the recovery rates of sericite and graphite were $89.7 \%$ and $11.3 \%$, respectively. The results of the FTIR spectra and zeta potential measurements demonstrated that the interaction of MF with graphite and sericite is mainly through electrostatic attraction. MF was preferred to adsorb on the surface of graphite, decreasing its zeta potential and improving its hydrophilicity more than that of sericite.
\end{abstract}

Keywords: surfactant; reverse flotation; graphite; sericite; adsorption

\section{Introduction}

Graphite is a type of widely used non-metallic material; large, flaky graphite is an irreplaceable raw material in many industries [1]. Natural graphite is found in three commercial varieties: crystalline flake, microcrystalline or amorphous, and crystalline vein or lump graphite [2]. Among them, crystalline flake graphite has the best floatability, followed by crystalline graphite; amorphous graphite has the poorest floatability. Due to the strong floatability of flake graphite, flotation is the most commonly used means of graphite beneficiation.

In conventional processing of large flaky graphite ores, a multistage grinding-flotation process is used to prevent large flakes from being destroyed during regrinding in graphite concentrate [3]. However, high-quality graphite resources that contain large graphite flakes are becoming increasingly scarce; moreover, fractional flaky graphite ores do not contain any large flakes and have relatively finely disseminated grain sizes. To increase the recovery of graphite, these graphite ores must be ground to a much smaller size. However, by doing so, gangue minerals are also ground finely. These fine/ultrafine gangue mineral particles not only affect sub-flotation processes in recovering valuable minerals based on true flotation but also lead to grade reduction through mechanical entrainment. Thus, the quality of final graphite concentrate is often greatly reduced due to the recovery of gangue minerals [4].

The separation efficiency between the valuable mineral and fully liberated and dispersed gangue is dependent on the degree of entrainment [5]. Unlike true flotation, which is selective, both gangue 
and valuable minerals alike can be recovered by entrainment. There are many factors that control the entrainment of hydrophilic gangue such as the properties of gangue, viscosity of the slurry, froth structure [6], particle mass [7], and shape [8]. Because entrainment has a detrimental effect on the grade of the concentrate, a number of studies have been carried out to research entrainment mechanisms, identify factors affecting entrainment and develop models with an objective of predicting entrainment in a flotation cell [4].

Sericite is one of the main gangue minerals in graphite ore and is also the main contaminant in graphite flotation concentrate. Moreover, thorough entrainment commonly reports to the concentrate in certain base metal ores [9]. The entrainment behavior of sericite in microcrystalline graphite flotation was studied by Hongqiang Li, who found that the entrainment of sericite leads to poor flotation selectivity of commercial microcrystalline graphite ore [10].

Although studies on the entrainment mechanism have been conducted for 30 years, no effective method has been found to control entrainment in graphite flotation. Thus far, there are two main methods to control entrainment in flotation [11]. The first method is ameliorating the flotation machine, such as optimizing the structure of flotation cell or flotation column [12-14]. The second method is optimizing the flotation technology and reagent system such as using polymer depressant for hydrophobic flocculation flotation. The use of a polymer depressant that has flocculability in flotation can not only cause the minerals that must be depressed to become hydrophilic but also increase the particle size of these minerals. Hence, bubble entrainment and mechanical entrainment in flotation can be weakened [15].

During graphite flotation, it is almost impossible to avoid the entrainment of sericite into graphite concentrate. Bartrum introduced the use of nigrosine as a depressant for graphite in lead zinc ore processing technology [16]. Carboxyl methylated cellulose (CMC) and dextrin can also be used as depressants of graphite [17]. However, few researchers have studied the reverse flotation of graphite in flotation when graphite is the objective mineral. This study used MF (formaldehyde condensate of methyl naphthalene sulfonic sodium salt) as a depressant for graphite during the flotation recovery of sericite. MF is actually a dispersant and a type of surfactant whose full name is formaldehyde condensate of methyl naphthalene sulfonic sodium salt. The formula and name of MF is shown in Figure 1. It is the formaldehyde condensate of methyl naphthalene sulfonate [18]. The lipophilicity naphthalene core of MF can adsorb on the nonpolar surface of particles with the sulfonate radical pointing to the solvent. The silfonate radical is hydrophilic; therefore, an energy barrier was formed around the dispersed particles, leading to mutual exclusion between them. The dispersed particles were then dispersed in the solvent uniformly [19].

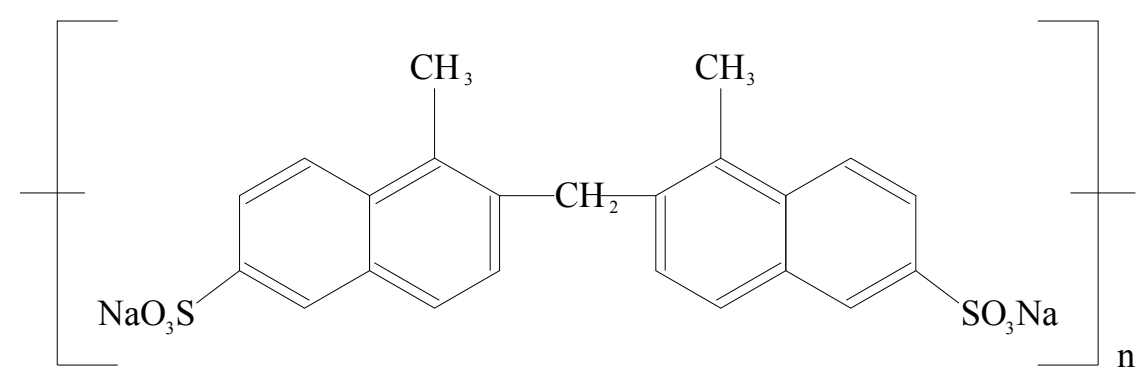

Figure 1. The formula and name of the depressant agent formaldehyde condensate of methyl naphthalene sulfonic sodium salt (MF).

To investigate the depressing effect of MF on graphite, batch flotation tests and contact angle measurements of single minerals and artificial mixtures composed of sericite and graphite single mineral and contact angle measurements were carried out. In the end, Fourier transform infrared spectroscopy (FTIR), X-ray photoelectron spectroscopy (XPS), and zeta potential measurements were performed to explain the adsorbing and depressing mechanism of MF. 


\section{Materials and Methods}

\subsection{Test Samples and Reagents}

The graphite single mineral sample was obtained from Yichang city in Hubei province, China. Large lumps of graphite with high purity were selected first. The lumps were then crushed to $-2 \mathrm{~mm}$ by a roll crushing mill followed by wet grinding in a conical ball mill with zirconia balls as grinding media; finally, the milled mineral particles were wet screened using 200 and 325 mesh US standard sieves, and the -74 to $+45 \mu \mathrm{m}$ size fraction was collected and used in batch flotation tests. According to the standard method (GB/T 3521-2008) [20] in China, the fixed carbon content (FC) of graphite single mineral was analyzed. The FC of graphite single mineral was $97.75 \%$ with an ash content of $2.25 \%$. Figure $2 \mathrm{a}$ is the $\mathrm{X}$-ray diffraction pattern of graphite single mineral, combined with the result of FC analysis, and indicates that the content of graphite in the sample was higher than $96 \mathrm{wt} \%$.
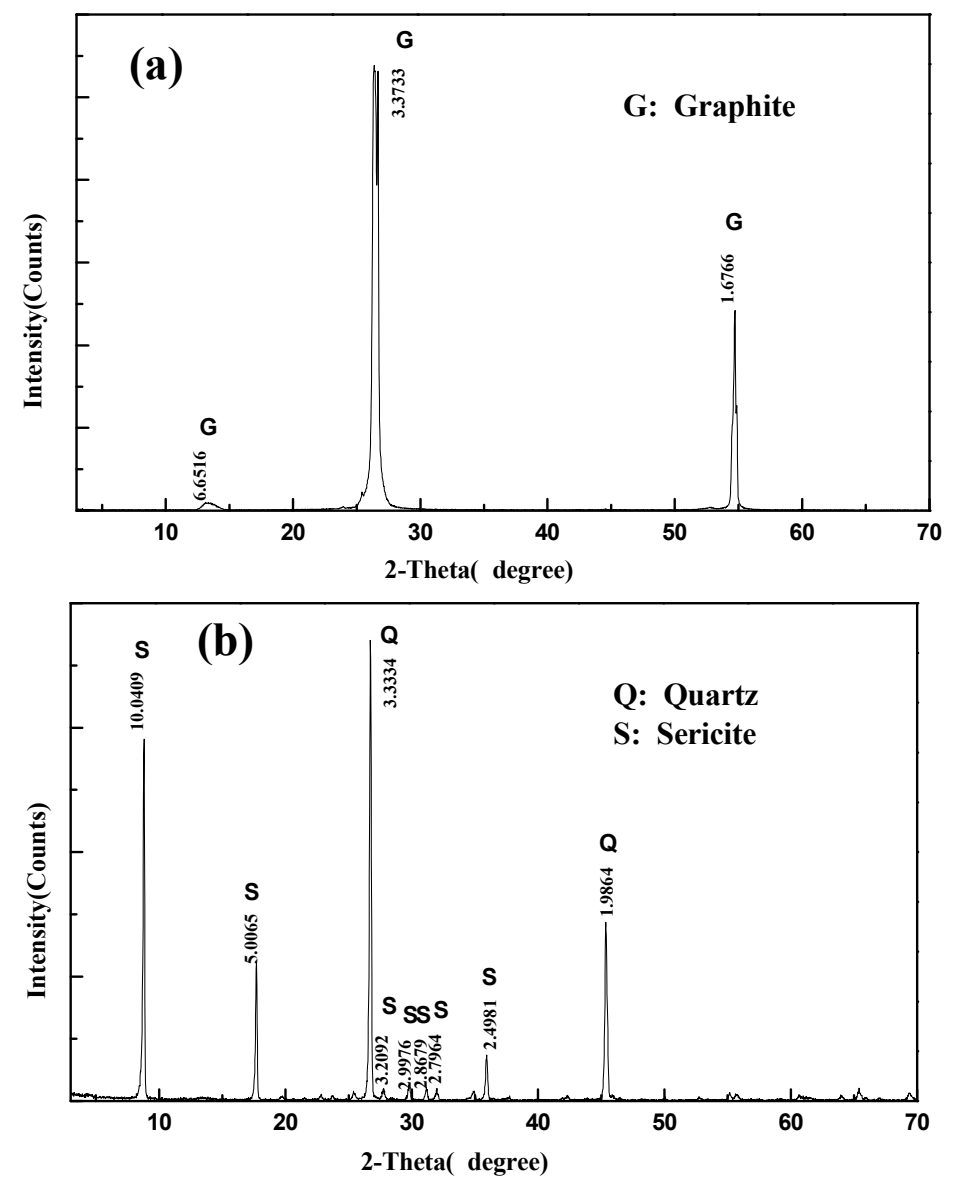

Figure 2. X-ray diffraction (XRD) patterns of single minerals. (a) Graphite single mineral; (b) sericite single mineral.

The sericite single mineral sample was obtained from Xianning city in Hubei province, China. It was processed by the same method as graphite. X-ray fluorescence (XRF) analysis indicated that it contained $9.17 \mathrm{wt} \% \mathrm{~K}_{2} \mathrm{O}, 1.09 \mathrm{wt} \% \mathrm{Na}_{2} \mathrm{O}, 37.04 \mathrm{wt} \% \mathrm{Al}_{2} \mathrm{O}_{3}$, and $48.51 \mathrm{wt} \% \mathrm{SiO}_{2}$. Figure $2 \mathrm{~b}$ shows the X-ray diffraction pattern of sericite, combined with the results of XRF analysis, and indicates that the content of sericite in the sample was higher than $93 \mathrm{wt} \%$.

Dispersant MF was used as the depressant of graphite in the tests and was purchased from Shandong Xiya Chemical Industry Co., Ltd. in Jinan, China. Dodecylamine acetate salt was used as the collector, and a frother for the experiments was purchased from Sinopharm Chemical Reagent Co., Ltd. in Shanghai, China. All regents were of analytical grade and used without further purification. 


\subsection{X-ray Powder Diffraction Analysis}

The crystalline structure and mineral composition of single mineral samples were determined by X-ray diffraction using a D8 Advance model X-ray powder diffractometer (Bruker Corporation, Stuttgart, Germany), with $\mathrm{Cu} \mathrm{K} \alpha$ radiation $(\lambda=1.5406 \AA)$ operated at a tube current of $40 \mathrm{~mA}$ and a voltage of $40 \mathrm{kV}$. Data of those samples were collected over $2 \theta$ values from $3^{\circ}$ to $70^{\circ}$ at a scan speed of $1^{\circ} / \mathrm{min}$.

\subsection{FTIR Spectroscopic Measurements and X-ray Photoelectron Spectroscopy (XPS)}

For the infrared studies, $2 \mathrm{~g}$ of single mineral were suspended in $200 \mathrm{~mL}$ of reagent solutions for $25 \mathrm{~min}$ at $\mathrm{pH}$ 7. The pulp was then centrifuged and washed at least three times with distilled water and dried under natural conditions. The infrared spectra of minerals were recorded using a Model Nicolet IS-10 spectrometer (Thermo Fisher Scientific, San Jose, CA, USA) through KBr disks in the range of 400-4000 $\mathrm{cm}^{-1}$. X-ray photoelectron spectroscopy (XPS) of samples were carried out on photoelectron spectrometer Multilab 2000 (Thermo VG Scientific, East Grinstead, UK)using an Al K $\alpha$ X-ray source operated at $200 \mathrm{~W}$ with $20 \mathrm{eV}$ pass energy. The vacuum pressure ranged from $10^{-9}$ to $10^{-8}$ Torr, and the takeoff angle was set at $90^{\circ}$.

\subsection{Contact Angle Measurement}

The assessments of wettability of single minerals were carried out on GBX MiniLab ILMS (GBX Scientific Instruments, Romans, France). The operating principle of the instrument is a washburn technique [21]. Each value recorded was the average of five separate determinations.

\subsection{Zeta Potential Measurement}

A suspension solution containing $0.1 \mathrm{wt} \%$ graphite single mineral particles that had been grounded to $-2.0 \mu \mathrm{m}$ in an eccentric vibration mill were prepared in a $5 \times 10^{-3} \mathrm{~mol} / \mathrm{dm}^{3} \mathrm{NaCl}$ solution and dispersed by MF for $10 \mathrm{~min}$. A certain amount of the suspension solution was then taken for zeta potential measurement. The zeta potentials were measured using a Malvern Zetasizer Nano ZS90 (Malvern Instruments, Malvern, UK) equipped with a rectangular electrophoresis cell. The suspension solution $\mathrm{pH}$ was adjusted to a desirable value by $\mathrm{HCl}$ or $\mathrm{NaOH}$ solutions. The conductivity and $\mathrm{pH}$ value of the suspension solution were monitored continuously during the measurement, and the environmental temperature was maintained at $25^{\circ} \mathrm{C}$. The results presented were the average of five independent measurements with a typical variation of $\pm 4 \mathrm{mV}$.

\subsection{Batch Flotation Tests of Single Mineral}

The flotation test was performed in an XFD flotation cell whose volume was near $140 \mathrm{~mL}$. First of all, the slurry was prepared by adding $2 \mathrm{~g}$ of graphite or sericite sample to $120-\mathrm{mL}$ solutions. Second, the depressant MF was added and conditioned for $5 \mathrm{~min}$ at an agitation speed of $1000 \mathrm{rpm}$ to allow MF adsorption. Following conditioning the collector, dodecylamine acetate salt was added and conditioned for $3 \mathrm{~min}$ at an agitation speed of $1400 \mathrm{rpm}$. The dosage of dodecylamine acetate salt was $200 \mathrm{mg} / \mathrm{L}$. Flotation was then performed for $3 \mathrm{~min}$. Finally, the floated and unfloated products were collected, and the flotation recovery was calculated based on the solid weight of products.

\subsection{Batch Flotation Tests of Artificial Mixture}

Sericite is one of the main gangue minerals in graphite ore. To investigate the effect of separating the sericite in graphite by reverse flotation, batch flotation tests of artificial mixture samples composed of sericite and graphite single mineral were carried out, and the mass ratio of graphite to sericite was 4:1. First of all, the slurry was prepared by adding $2.5 \mathrm{~g}$ of the artificial mixture sample to $120 \mathrm{~mL}$ of solution. Second, the depressant MF was added and conditioned for $5 \mathrm{~min}$ at an agitation speed of $1000 \mathrm{rpm}$ to allow MF adsorption. Followed the collector dodecylamine, acetate salt was added and 
conditioned for $3 \mathrm{~min}$ at an agitation speed of $1400 \mathrm{rpm}$. The pulp $\mathrm{pH}$ was adjusted to a desirable $\mathrm{pH}$ value by $\mathrm{HCl}$ or $\mathrm{NaOH}$ solutions before the collector was added. Flotation was then performed for $3 \mathrm{~min}$. Finally, the floated and unfloated products were collected. The recovery of graphite and sericite in floated products can be calculated by Equations (1) and (2).

$$
\begin{gathered}
R_{s}=\left(1-\frac{2\left(m_{2}-m_{1} A_{g}\right)}{A_{s}-A_{g}}\right) \times 100 \% \\
R_{g}=\left(1-\frac{m_{1} A_{s}-m_{2}}{2\left(A_{s}-A_{g}\right)}\right) \times 100 \%
\end{gathered}
$$

$R_{S}$ - the recovery of sericite in floated product (\%);

$R_{g}$ - the recovery of graphite in floated product (\%);

$m_{1}$-the weight of unfloated product $(\mathrm{g})$;

$m_{2}$-the ash weight of unfloated product $(\mathrm{g})$;

$A_{S}$ - the ash content of sericite single mineral (\%);

$A_{g}$ - the ash content of graphite single mineral (\%).

\section{Results and Discussion}

\subsection{The Wettability of Graphite and Sericite}

Froth flotation is a process of separating valuable minerals from gangues by exploiting differences in their surface wettability. To assess the wettability of sericite and graphite, the contact angles of single minerals were measured. The effect of MF concentration on the wettability of sericite and graphite powder is shown in Figure 3.
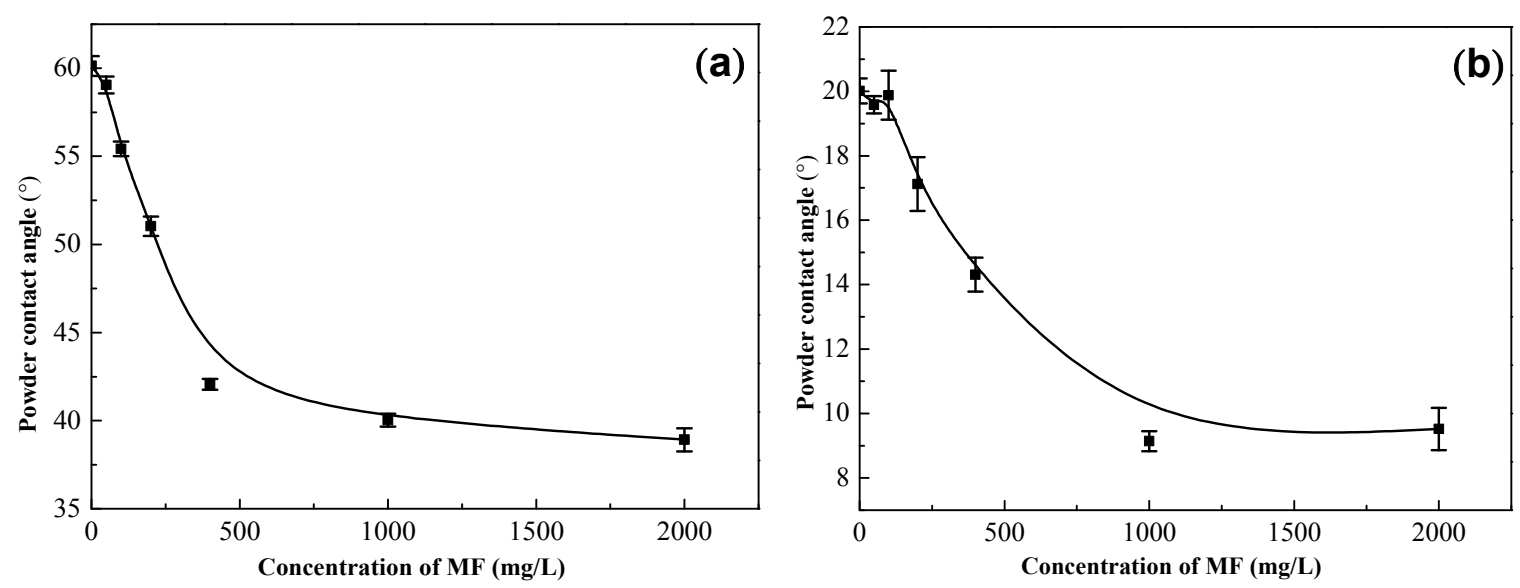

Figure 3. Powder contact angle of graphite (a) and sericite (b) as a function of MF concentration.

The initial contact angle of sericite powder was $20.0^{\circ}$. This indicated that the surface of sericite was hydrophilic, which agreed with the result of Gao [22]. The initial contact angle of graphite powder was $60.1^{\circ}$, suggesting that it was a hydrophobic mineral.

From Figure 3, when the MF concentration was increased from 0 to $2000 \mathrm{mg} / \mathrm{L}$, the contact angle of graphite decreased from $60.1^{\circ}$ to $38.9^{\circ}$, suggesting that graphite became moderately hydrophilic. Compared with graphite powder, the contact angle of hydrophilic sericite powder decreased from $20.0^{\circ}$ to $9.5^{\circ}$ slightly.

\subsection{Batch Flotation of Single Mineral}

To investigate the depressing effect of MF concentration on sericite and graphite, batch tests of single minerals were conducted, and the test results are shown in Figure 4. 

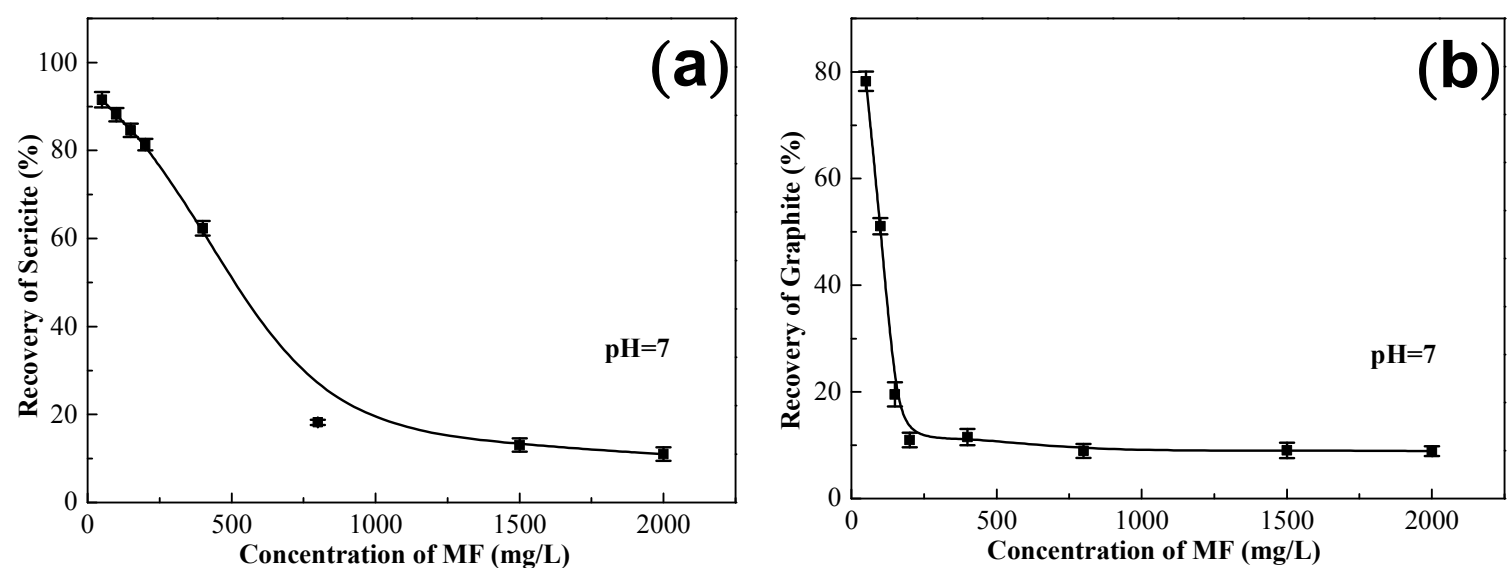

Figure 4. Recovery of sericite (a) and graphite (b) as a function of MF concentration.

Sericite recovery decreased sharply with an increasing MF concentration from 50 to $800 \mathrm{mg} / \mathrm{L}$, and the sericite recovery decreased from $91.6 \%$ to $18.2 \%$. The sericite recovery continuously decreased slightly to $10.99 \%$ as the MF concentration further increased to $2000 \mathrm{mg} / \mathrm{L}$.

The graphite recovery sharply decreased from $78.2 \%$ to $11.0 \%$ with an increasing MF concentration from 50 to $200 \mathrm{mg} / \mathrm{L}$ and then leveled off above $200 \mathrm{mg} / \mathrm{L}$. As the MF concentration further increased to $2000 \mathrm{mg} / \mathrm{L}$, the recovery of graphite changed little and was approximately $10 \%$.

The foregoing results showed that the recovery of both graphite and sericite decreased as MF concentration increased. However, the recovery of graphite decreased more sharply than that of sericite. When the concentrate of MF increased to $200 \mathrm{mg} / \mathrm{L}$, the sericite recovery decreased to $81.3 \%$, whereas the recovery of graphite had already decreased to $11.0 \%$. With a continued increase in the MF concentration, the graphite recovery remained at approximately $10 \%$; however, the recovery of sericite continuously decreased. The difference in recovery between graphite and sericite was due to the difference in floatability between graphite and sericite after interaction with MF. This difference creates opportunities for separating the sericite from graphite.

\subsection{Batch Flotation of Artificial Mixtures}

To determine the effect of MF concentration and pulp $\mathrm{pH}$ value on the separation of sericite and graphite, batch flotation tests of artificial mixtures were carried out.

\subsubsection{Effect of MF Concentration}

From the test results of single minerals, sericite and graphite were both depressed by MF. However, the effect of the depression was affected by the concentration of MF. The recovery of graphite and sericite showed a general declining trend as MF concentration increased. To fully separate sericite from graphite, the difference in recovery between graphite and sericite should be sufficiently large. When the MF concentration was $50-400 \mathrm{mg} / \mathrm{L}$, the recovery of sericite was $62.3 \%-91.6 \%$, whereas the recovery of graphite was $11.5 \%-78.2 \%$; in this range of MF concentration, the difference in recovery between graphite and sericite was significant. Hence, tests were conducted at different MF concentrations ranging from 50 to $600 \mathrm{mg} / \mathrm{L}$ with a pulp $\mathrm{pH}$ of 7 . The results were as shown in Figure 5. 

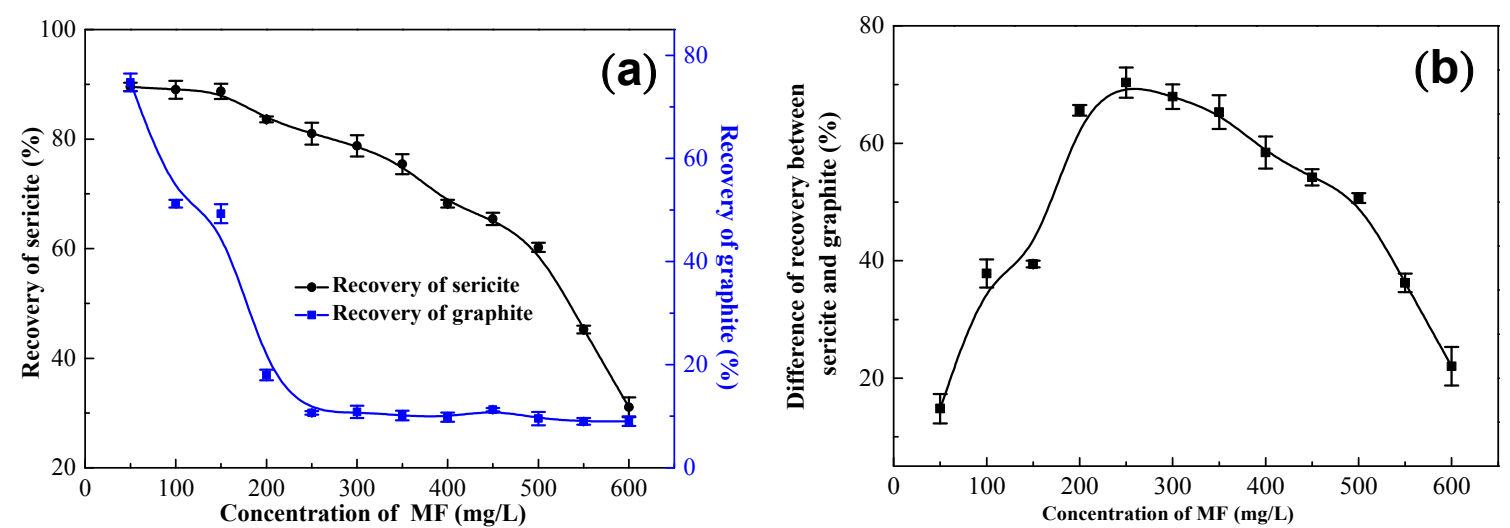

Figure 5. Recovery of sericite and graphite (a) and the difference in recovery between graphite and sericite $(\mathbf{b})$ as a function of MF concentration.

It can be seen from Figure 5 that the recovery of both graphite and sericite decreased as MF concentration increased, whereas the difference in the recovery between graphite and sericite increased firstly and then began to decrease above $250 \mathrm{mg} / \mathrm{L}$. As MF concentration increased, graphite recovery showed a sharper decline than did sericite. When the MF concentration increased to $250 \mathrm{mg} / \mathrm{L}$, the difference in recovery between graphite and sericite reached a maximum difference of $70.4 \%$. Simultaneously, the recovery of graphite and sericite was $10.6 \%$ and $81.0 \%$, respectively. When the concentration of MF was further increased, the graphite recovery did not change, and the sericite recovery continued to decrease to $31.0 \%$. The difference in recovery between graphite and sericite began to decrease with a further increase of MF concentration above $250 \mathrm{mg} / \mathrm{L}$. Hence, to separate sericite from graphite more effectively, an MF concentration of $250 \mathrm{mg} / \mathrm{L}$ was selected as optimum for the separation.

\subsubsection{Effect of $\mathrm{pH}$}

The pulp $\mathrm{pH}$ affected the surface potential of mineral particle surface, thereby affecting the adsorption of depressant MF on the surface of mineral particles. Hence, the depressing effect on the mineral is affected by the pulp $\mathrm{pH}$. The effects of pulp $\mathrm{pH}$ on the separation of sericite from graphite were studied by artificial mixture flotation tests. The pulp pH varied from 2 to 12 with a $250 \mathrm{mg} / \mathrm{L}$ MF concentration. The tests results were as shown in Figure 6.
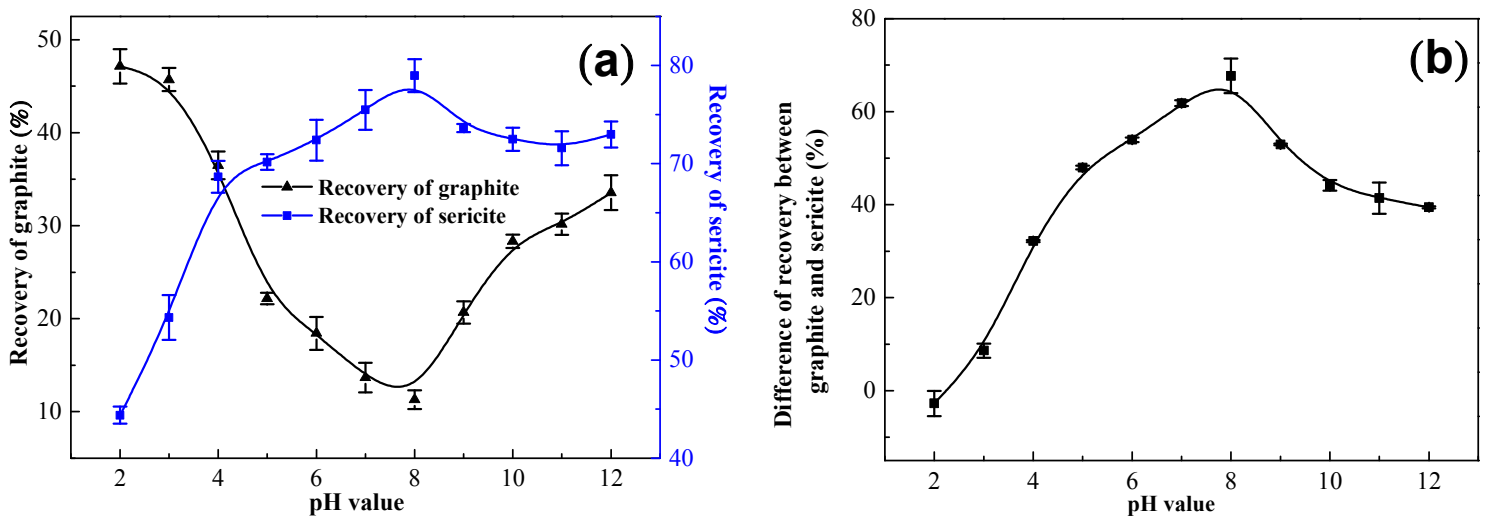

Figure 6. Recovery of sericite and graphite (a) and the difference in recovery between graphite and sericite $(\mathbf{b})$ as a function of pulp $\mathrm{pH}$ value.

From Figure 6, the graphite recovery decreased sharply with increasing pulp pH value from 2 to 8 and then increased strongly above $\mathrm{pH} 8$. The sericite recovery increased with increasing pulp $\mathrm{pH}$ from 
2 to 8 and then varied slightly above $\mathrm{pH}$. The difference in recovery between graphite and sericite increased sharply with an increasing pulp pH value from 2 to 8 and then decreased slightly above $\mathrm{pH}$ 8. The separation of sericite from graphite was optimal at a pulp $\mathrm{pH}$ of 8 with the recovery of graphite and sericite of $11.3 \%$ and $79.0 \%$, respectively.

\subsection{FTIR Spectra of Minerals Before and After Interaction with MF}

To study the mechanism of MF in the flotation separation of sericite from graphite, the IR (infrared) spectra of these two minerals before and after interacting with reagents were measured, and the results are shown in Figures 7 and 8.

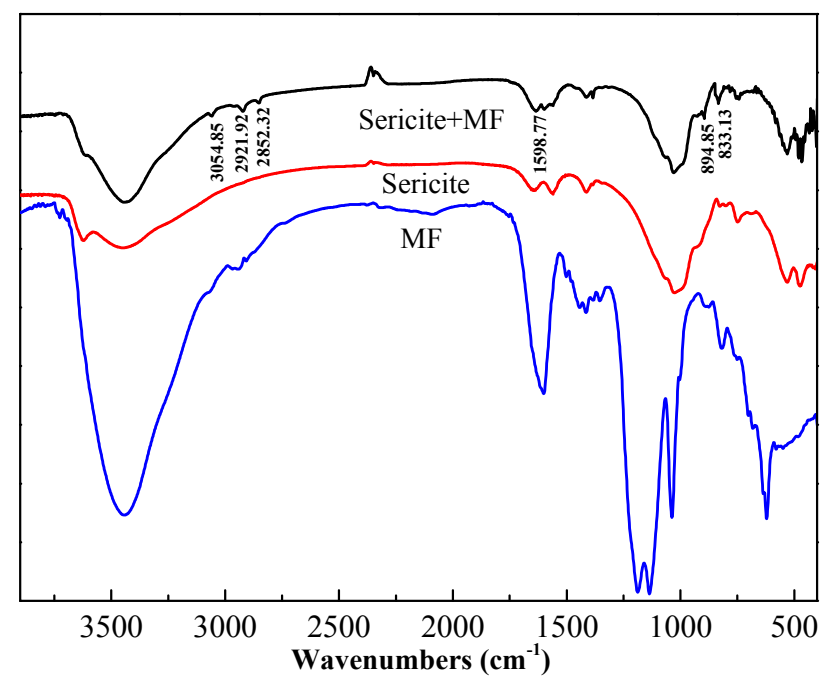

Figure 7. FTIR spectra of sericite before and after interaction with MF.

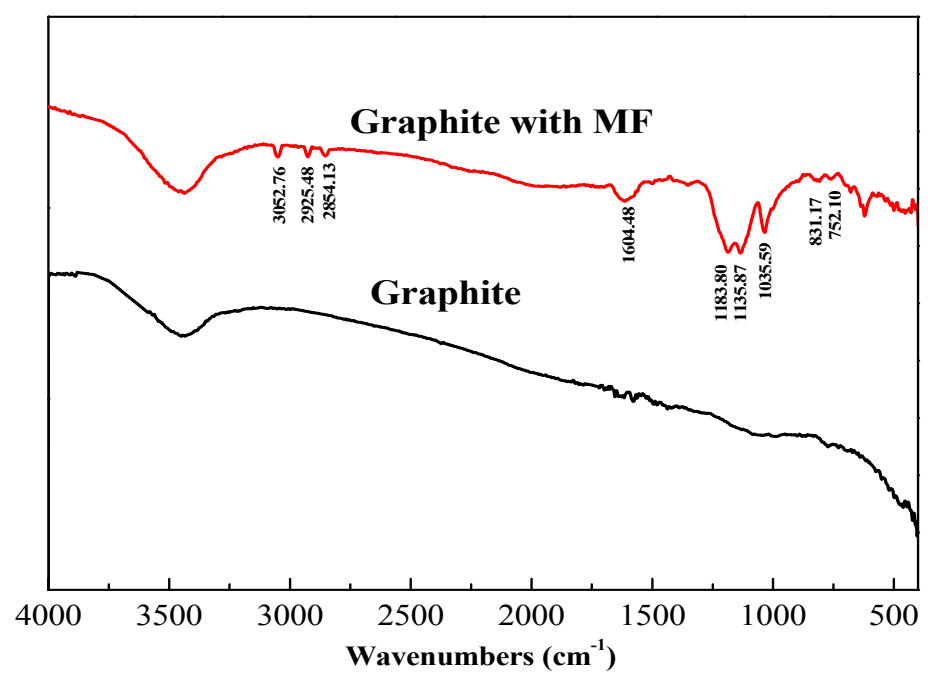

Figure 8. FTIR spectra of graphite before and after interaction with MF.

After interaction with MF, the stretching bands of $-\mathrm{CH}_{3}$ and $-\mathrm{CH}_{2}$ groups in MF molecules appeared at approximately 2922 and $2852 \mathrm{~cm}^{-1}$ on sericite surfaces and 2926 and $2854 \mathrm{~cm}^{-1}$ on graphite surfaces, respectively [23]. The stretching bands of $=\mathrm{CH}_{2}-$ groups on naphthalene nucleus in MF molecules appeared at approximately $3055 \mathrm{~cm}^{-1}$ on sericite surfaces and $3053 \mathrm{~cm}^{-1}$ on graphite surfaces, respectively. New bands appeared at 895 and $833 \mathrm{~cm}^{-1}$ on sericite surfaces and at 831 and $752 \mathrm{~cm}^{-1}$ on graphite surfaces due to the bending vibrations of solitary hydrogen groups on the 
naphthalene nucleus in MF molecules [24]. Moreover, the vibration bands of the naphthalene nucleus skeleton in MF molecules appeared at approximately $1599 \mathrm{~cm}^{-1}$ on sericite surfaces and $1605 \mathrm{~cm}^{-1}$ on graphite surfaces. The bands that appeared at 1184,1136 and $1035 \mathrm{~cm}^{-1}$ on the graphite surfaces were the adsorption bands of $-\mathrm{SO}_{3}$ groups in MF molecules [24]. The results of FTIR spectra demonstrated that, after MF treatment, no new adsorption peaks appeared on sericite and graphite surfaces except for MF's adsorption bands, which implied that MF might adsorb onto the two minerals without the formation of new complexes.

As an alternative to FTIR, the XPS analysis of samples was carried out. The XPS survey spectra of graphite and sericite after interaction with MF was shown in Figure 9. It can be seen from Table 1 that $\mathrm{S}$ and $\mathrm{Na}$ elements appear on the surface of graphite and sericite. Meanwhile, the changes in electron binding energy $\left(\Delta \mathrm{E}_{\mathrm{B}}\right)$ of $\mathrm{C}, \mathrm{O}$ and $\mathrm{S}$ elements after treatment with MF were relatively small, which is less than the error value of experiment equipment. That means the interaction between MF and graphite or sericite was physical adsorption without the formation of new complexes [25]. XPS spectra agree well with FTIR results and confirm physical adsorption occurred on graphite and sericite surface.

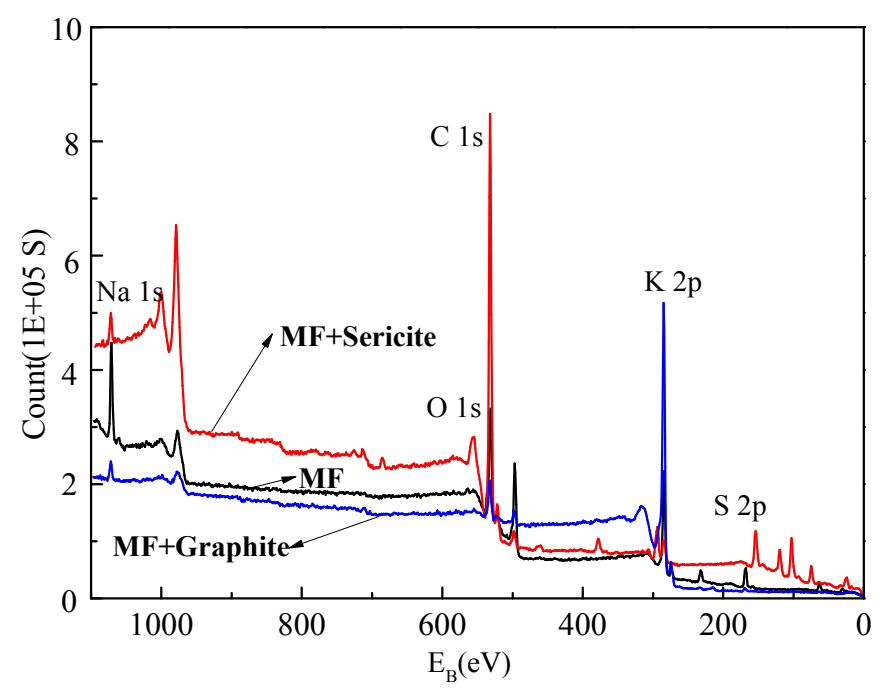

Figure 9. X-ray photoelectron spectroscopy (XPS) survey spectra of graphite and sericite after interaction with MF.

Table 1. X-ray photoelectron spectroscopy (XPS) analysis results of graphite and sericite after interaction with MF.

\begin{tabular}{cccccc}
\hline \multirow{2}{*}{ Sample } & \multicolumn{5}{c}{ Electron Binding Energy, $\mathbf{E}_{\mathbf{B}} / \mathbf{e V}$} \\
\cline { 2 - 6 } & $\mathbf{C 1 s}$ & O1s & S2p & Na1s & K2p \\
\hline MF & 284.62 & 531.68 & 168.62 & 1071.68 & - \\
MF + Sericite & 284.64 & 531.80 & 168.24 & 1072.08 & 293.23 \\
$\Delta \mathrm{E}_{\mathrm{B}} / \mathrm{eV}$ & 0.02 & 0.12 & -0.38 & 0.40 & - \\
$\mathrm{MF}+\mathrm{Graphite}$ & 284.62 & 532.44 & 169.35 & 1072.21 & - \\
$\Delta \mathrm{E}_{\mathrm{B}} / \mathrm{eV}$ & 0 & 0.76 & 0.73 & 0.53 & - \\
\hline
\end{tabular}

The mechanism of graphite reaction with MF is shown in Figure 10. The figure illustrates that the hydrophobic naphthalene core could adsorb onto the surface of graphite particles preferentially with the sulfonate radical pointing to the water. The surface tension of particles decreases due to the association between the sulfonate radical of the MF molecule and the hydroxyl in the water [26], so hydrophobic graphite particles become hydrophilic. The contact angle of graphite decreased after the reaction with MF. In flotation, the depressing effect of MF on graphite was achieved by transforming the surface of graphite particles from hydrophobic to hydrophilic, and then the graphite cannot float. 
The adsorption of MF onto sericite surface also improves its hydrophilicity, and the pre-adsorption of MF interferes with the adsorption of dodecylamine onto sericite surface [27]. This is the mechanism of MF's depressing effect on sericite in the flotation.

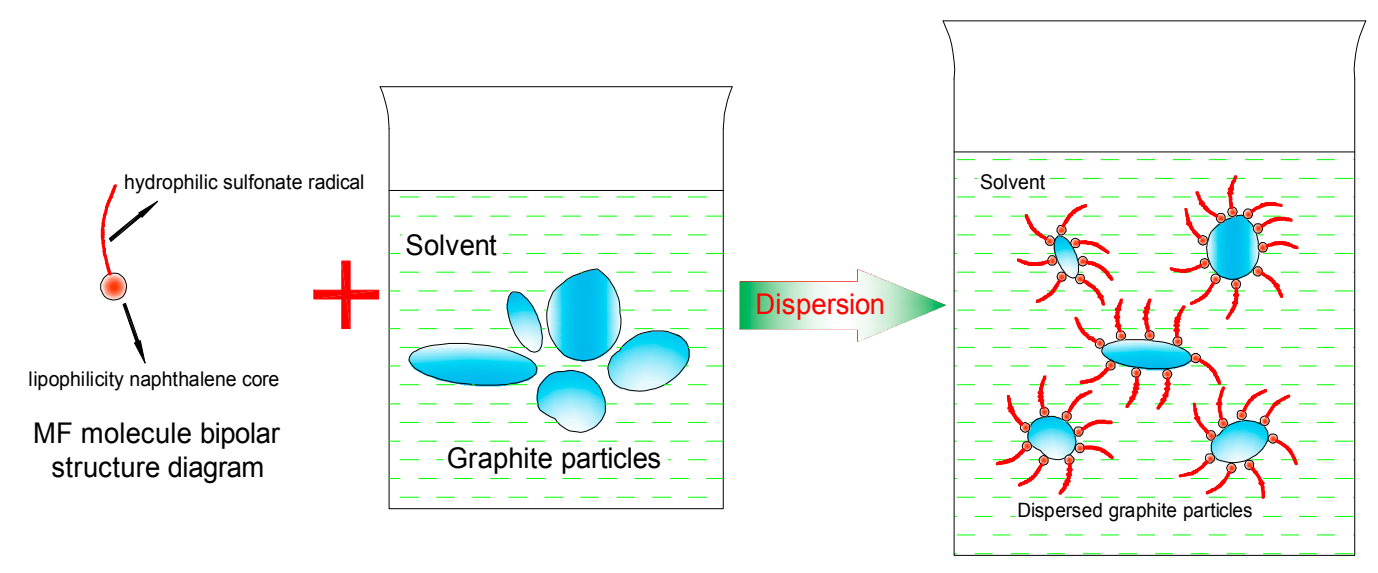

Figure 10. The MF molecule adsorption at the interphase of graphite-solvent.

In flotation, the sericite and graphite did not have sufficient adsorption of MF on their surfaces when the MF concentration was comparatively small. Hence, the recovery of graphite and sericite did not have a significant decline. As MF concentration increased, due to the sufficient adsorption and selective adsorption of MF on the surface, graphite was intensely depressed and the graphite recovery sharply decreased. Meanwhile, the adsorption of MF on the surface was not adequate enough to lead to the intensely depressing effect on sericite. Therefore, the recovery of sericite was much higher than that of graphite. With the further increase in MF concentration, sericite floated worse due to interference with the adsorption of dodecylamine from the sufficient adsorption of MF on the surface of sericite. Hence, the recovery of sericite similarly had a sharp decrease.

\subsection{Zeta Potential Measurement}

Zeta potentials of minerals before and after interaction with MF are shown in Figures 11 and 12.

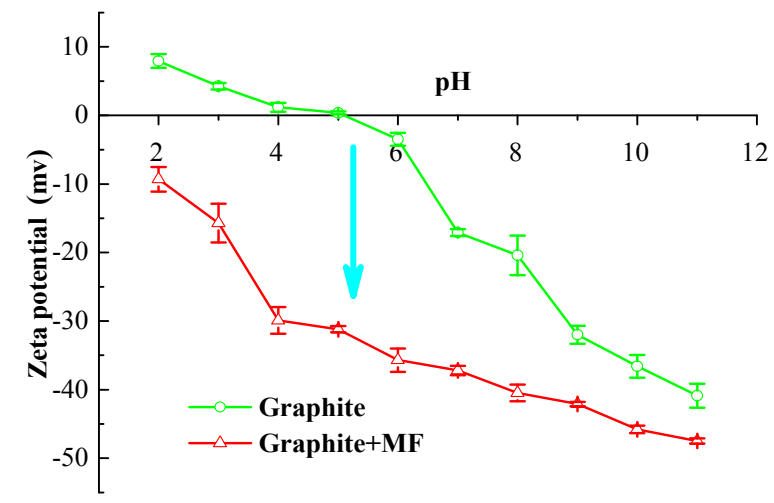

Figure 11. Zeta potentials of graphite before and after interaction with MF (concentration = $250 \mathrm{mg} / \mathrm{L}$ ). 


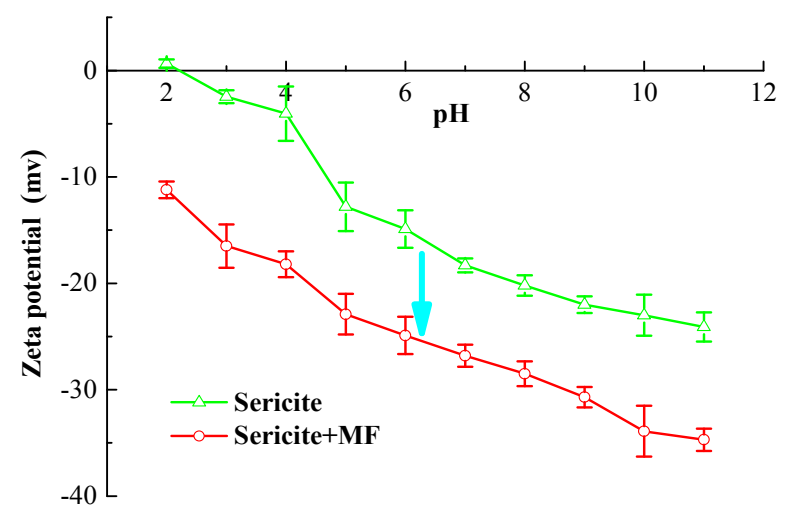

Figure 12. Zeta potentials of sericite before and after interaction with MF (concentration $=250 \mathrm{mg} / \mathrm{L}$ ).

The surface of graphite and sericite varied from positively charged to negatively charged as $\mathrm{pH}$ value increased. The isoelectric points (IEPs) corresponded to $\mathrm{pH}$ values of approximately $\mathrm{pH} 2.0$ for sericite and $\mathrm{pH} 4.9$ for graphite. The surface of graphite was slightly positive due to the adsorption of $\mathrm{H}^{+}, \mathrm{OH}^{-}$, or some other ions between $\mathrm{pH} 2$ and 5 . The zeta potential of graphite and sericite showed a pronounced shift towards more negative zeta potentials in the presence of $\mathrm{MF}$, indicating that the anionic Gemini molecules adsorbed onto graphite and sericite [28]. Moreover, after interacting with $\mathrm{MF}$, the zeta potential of graphite was much more negative than that of sericite, demonstrating that MF was preferred to adsorb on graphite surfaces. The FTIR results implied that MF might adsorb onto the two minerals without the formation of new complexes. The negatively charged MF adsorb on the negatively charged graphite byhydrophobic/van der Waals interaction between the benzene rings of MF and the graphite hydrocarbon rings at $\mathrm{pH}>$ IEP [29]. However, the negatively charged MF adsorb on the negatively charged sericite by hydrogen bond at $\mathrm{pH}>\mathrm{IEP}[30,31]$. Obviously, the hydrophobic/van der Waals interaction energy between the nonpolar benzene rings of MF and the nonpolar graphite hydrocarbon rings are much stronger than the hydrogen bond energy between MF and sericite. Therefore, the MF appears to be preferentially selective to the graphite surface relative to the sericite surface.This can explain why the recovery of graphite decreased more sharply than did sericite as MF concentration increased.

\section{Conclusions}

Batch flotation experiments of single mineral and artificial mixtures of flaky graphite-sericite and contact angle measurements were conducted to verify the feasibility of reverse flotation separation of sericite from graphite by using a Gemini surfactant: MF. FTIR spectra and zeta potential measurements were conducted to confirm the mechanism of MF reaction with sericite and graphite.

The results of contact angle measurements indicate that MF can improve the hydrophilicity of graphite and sericite. The flotation results of single minerals indicated that MF displayed a depression of both graphite and sericite, but the recovery of graphite declined more sharply than sericite as MF concentration increased. The results of artificially mixed mineral flotation demonstrated the preferential flotation separation of sericite from graphite with a pulp $\mathrm{pH}$ at 8 with an MF concentration of $250 \mathrm{mg} / \mathrm{L}$; the recovery rates of sericite and graphite were $89.7 \%$ and $11.3 \%$, respectively. Sericite can be separated from graphite by reverse flotation separation.

The interaction of MF with graphite and sericite surfaces was dominantly hydrophobic/van der Waals interaction and hydrogen bond, which was confirmed by FTIR spectra, X-ray photoelectron spectroscopy. MF was preferred to adsorb onto the surface of graphite, decreasing its zeta potentials and improving its hydrophilicity relative to sericite. This was confirmed by zeta potential measurement.

The reverse flotation separation of sericite from graphite can dramatically reduce the infusion of sericite in the flotation concentrate. However, in this paper, all test samples were single minerals. Tests should be conducted with practical ore samples to evaluate the effectiveness of the MF reagent. 
Acknowledgments: The authors would like to acknowledge the financial support from the Fundamental Research Funds for Central Universities of China (No. WUT: 2014-IV-071) and technical support from the Center for Analysis of Wuhan University of Technology.

Author Contributions: Yangshuai Qiu conceived and designed the experiments, performed the experiments, and wrote the paper under the supervision of Yongfu Yu and Lingyan Zhang. Zhijun Ouyang analyzed the data. Yupeng Qian and Yangshuai Qiu revised the manuscripts and approved the manuscripts.

Conflicts of Interest: The authors declare no conflict of interest.

\section{References}

1. Inagaki, M.; Toyoda, M.; Kang, F.Y.; Zheng, Y.P.; Shen, W.C. Pore structure of exfoliated graphite-A report on a joint research project under the scientific cooperation program between NSFC and JSPS. New Carbon Mater. 2003, 18, 241-249.

2. Crossley, P. Graphite-High-tech supply sharpens up. Ind. Miner. 1999, 386, 31-47.

3. Yue, C.L. Study on the damage of large-scale flaky graphite and new grinding-flotation process. Non Met. Mines. 2002, 25, 36-37.

4. Wang, L.; Peng, Y.; Runge, K.; Bradshaw, D. A review of entrainment: Mechanisms, contributing factors and modelling in flotation. Miner. Eng. 2015, 70, 77-91. [CrossRef]

5. Ross, V.E. Flotation and entrainment of particles during batch flotation tests. Miner. Eng. 1990, 3, $245-256$. [CrossRef]

6. Neethling, S.J.; Cilliers, J.J. The entrainment factor in froth flotation: Model for particle size and other operating parameter effects. Int. J. Miner. Process. 2009, 93, 141-148. [CrossRef]

7. Ata, S. Phenomena in the froth phase of flotation-A review. Int. J. Miner. Process. 2012, 102-103, 1-12. [CrossRef]

8. Kirjavainen, V.M. Review and analysis of factors controlling the mechanical flotation of gangue minerals. Int. J. Miner. Process. 1996, 46, 21-34. [CrossRef]

9. Silvester, E. The recovery of sericite in flotation concentrates. Miner. Process. Extr. Metall. Rev. 2011, 120, 10-14. [CrossRef]

10. Li, H.Q.; Feng, Q.M.; Yang, S.Y.; Ou, L.M.; Lu, Y. The entrainment behaviour of sericite in microcrystalline graphite flotation. Int. J. Miner. Process. 2014, 127, 1-9. [CrossRef]

11. Shi, H. Study on the Mechanism of Improving Flotation Efficiency by Using Oscillametric Method. Master's Thesis, Coal Science Research Institute Tangshan Branch, Tangshan, China, 2001.

12. Valderrama, L.; Santander, M.; Paiva, M. Modified-three-product column (3PC) flotation of copper-gold particles in a rougher feed and tailings. Miner. Process. 2011, 24, 1397-1401. [CrossRef]

13. Rubio, J. Modified column flotation of mineral particles. Miner. Process. 1996, 48, 183-196. [CrossRef]

14. Li, B. Study on Flotation Behaviour of High ASH Fine Silt Particles Inrotational Flow-MicrovesicleSedimentation Combined Flow. Master's Thesis, China University of Mining and Technology, Xuzhou, China, 2013.

15. Peng, Y.; Ourriban, M.; Pelltier, P.; Giraed, J.; Jang, H.; Liu, Q. Reduction of fine quartz entrainment in chalcopyrite flotation by polymer depressants. In Proceedings of 23rd International Mineral Processing Congress, Istanbul, Turkey, 3-8 September 2006; pp. 548-553.

16. Bartrum, J.; Dobrowolski, H.J.; Schache, I.S. Devolopment in Milling of Silver/Lead/Zinc Ore in the Mount Isa Areas Scine 1970, Lead-Zinc Update; Americal Institute of Mining, Metallurgical and Petroleum Engineers Inc.: New York, NY, USA, 1977; pp. 1279-1289.

17. Zhang, J.S.; Que, X.L. Beneficiation Reagent, 2nd ed.; Metallurgical Industry Press: Beijing, China, 2008; pp. 234-236.

18. Ye, H.M. Study on the Synthesis of the Dispersing Agent MF. Master's Thesis, East China Institute of Technology, Shanghai, China, 2014.

19. Wang, G.P. Oil methyl naphthalene preparation of dispersant MF. Exquisite Spec. Chem. 2000, 2, $16-17$.

20. Xianyang Institute of Non-Metallic Minerals. GB/T 3521-2008, Methods for Chemical Analysis of Graphite; Standardization Administration of China: Beijing, China. (In Chinese)

21. Chibowski, E.; Perea-Carpio, R. Problems of contact angle and solid surface free energy determination. Adv. Colloid Interface Sci. 2002, 98, 245-264. [CrossRef] 
22. Gao, H.M.; Yuan, J.Z.; Wang, X.R.; Guan, J.F.; Zhang, L.Y.; Jing, Z.Q.; Mao, Y.L. Mechanism of surface modification for sericite. J. Wuhan Univ. Technol. Mater. Sci. Ed. 2007, 22, 470-472. [CrossRef]

23. Yang, H.F.; Tang, Q.Y.; Wang, C.L.; Zhang, J.L. Flocculation and flotation response of Rhodococcus erythropolis to pure minerals in hematite ores. Miner. Eng. 2013, 45, 67-72. [CrossRef]

24. Wu, X.R. Study of Structure Characterization and Condensation Process of Sodium Salts of Naphthalene Sulfonated Formaldehyde. Master's Thesis, Zhejiang University, Hangzhou, China, 2006.

25. Luo, X.M.; Yin, W.Z.; Wang, Y.F.; Sun, C.Y.; Ma, Y.Q.; Liu, J. Effect and mechanism of dolomite with different size fractions on hematite flotation using sodium oleate as collector. J. Cent. South Univ. 2016, 23, 529-534. [CrossRef]

26. Xu, Z.Y.; Fan, C.L. Dispersing action of tannic acid for determining granularity distribution characteristics of graphite powder with laser method. Carbon Tech. 2009, 28, 1-5.

27. Sun, C.Y.; Yin, W.Z. The Flotation Mechanism of Silicate Minerals, 1st ed.; Science Press: Beijing, China, 2001; pp. 113-148.

28. Huang, Z.Q.; Zhong, H.; Wang, S.; Xia, L.Y.; Zou, W.B.; Liu, G.Y. Investigations on reverse cationic flotation of iron ore by using a Gemini surfactant: Ethane-1,2-bis(dimethyl-dodecyl-ammonium bromide). Chem. Eng. J. 2014, 257, 218-228. [CrossRef]

29. Zhu, J.G. Hydrocarbon oil collector. In Chemical Principle of Flotation Reagents, 1st ed.; Metallurgical Industry Press: Beijing, China, 1996; pp. 3-5. (In Chinese)

30. Zhu, J.G. Organic depressant. In Chemical Principle of Flotation Reagents, 1st ed.; Metallurgical Industry Press: Beijing, China, 1996; pp. 267-271. (In Chinese)

31. Sun, C.Y.; Yin, W.Z. Flotation Principle of Silicate Minerals, 1st ed.; Science Press: Beijing, China, 2001; pp. 323-328. (In Chinese)

(C) 2016 by the authors; licensee MDPI, Basel, Switzerland. This article is an open access article distributed under the terms and conditions of the Creative Commons Attribution (CC-BY) license (http:/ / creativecommons.org/licenses/by/4.0/). 